\title{
Sustainable reconstruction and planning strategies for Afghan cities: conservation in cultural and environmental heritage
}

\author{
B. A. Kazimee \\ School of Architecture and Construction Management, \\ Washington State University, USA
}

\begin{abstract}
The reconstruction process of Afghan cities demands a sustainable course of development so that once again they can resurrect their once vital and attractive human-environmental capacities. In this paper effort has been made to present strategies and explore processes whose intent is to point to a rediscovery of the art and science of designing a sustainable course of development. It seeks to synthesize the principles of sustainability into an agenda for the design of towns and cities. These strategies serve as indicators to sustainable development; they should be used to define inherent qualities, carrying capacities and required ecological footprints of a place. Furthermore they are established to allow designers to model, measure and program sustainable standards as well as monitor the regenerative process of cities.
\end{abstract}

\section{Introduction}

The post war reconstruction of Afghan cities poses critical questions to the Afghan professionals who along with the world community, now struggle to shape the built environment of this 25 years war stricken country. A deadly war which was imposed on Afghanistan, first by the hegemonies of Soviet Union in 1978 which lingered for 14 years and then the calamity of civil war and the avaricious contest of warlords for power and regional control, suffocated the course of any progress and development to this day. The calamity of war not only resulted in the tragic loss of a million lives and into mass exodus of its indigenous population, but even more tragic was the complete destruction of its built environments, including those of the Afghan hinterland, leaving behind utter chaos and destruction. 
The prewar cities held the capacity of conscious interaction between its people and the natural environment. Here, the living quarters were composed of intimately bonded communities joined by a rich tapestry of culture and social rituals. The evolution of cities and towns took their sustainable course and evolved out of necessity, being in tune with the ecology and regional fit. The natural environment was preserved with religious fervor and respect. In the words of Edward Secler; "one of the many sad consequences of the recent war years is that public attention stayed riveted to the topical political events and largely failed to take cognizance of the tremendous cultural wealth that was destroyed in fighting or is still threatened with destruction owing to the introduction of changing ways of life." [2]

The design guidelines for sustainable and affordable development discussed below are organized under five primary variables. They are Human ecology, Energy conservation, Land and resource conservation, and Water quality.

\section{Human ecology: the way people interrelate and use the environment}

\subsection{Regional design strategies}

It is necessary to provide a balance opportunity between critical human activities and those of environmental interchanges in the region. This can be achieved by providing and enhancing greenbelts and water ways systems to improve and balance the air quality and water cycles. The greenbelt moderates climate extremes, increases recreational opportunities and bio-diversity. These green programs should use primarily indigenous landscaping which conserve water, reduces maintenance and celebrates the unique qualities of region. Family farming should also be encouraged in allotment gardens in the green belt. Conservation of farm land, natural forests and water ways in the rural zones around the cities are already a resourceful environmental capital to be restored and their ecological integrity should be enhanced.

Spring water runoff should be retained in balancing lakes (artificial/ natural retention ponds and reservoirs) which supplements dry seasons, reduces spring flooding, filters eroded soils, improves water quality, provide and recreation potentials [3].

Trees are critical for human comfort and balancing the carbon to oxygen cycle $\left(\mathrm{CO}_{2} \leftrightarrow \mathrm{O}_{2}\right)$. Cities need to balance this critical oxygen producing cycle by planting more trees. Green areas increase the desirability of residential areas. Saving wetlands and creating urban forest, can enhance recreation, livability and sustainability. Trees absorb toxins from the air, create oxygen, shade and cool the environment through evaporative transpiration, and add to the ambient humidity of indoor and outdoor spaces.

\subsection{City design strategies}

Afghan cities throughout history played a conscious role in catering to the needs of commerce and cultural activities of not only its own population, but to the life-line of the merchants and trade in the whole region. Their ancient importance 
has been prominent and described by intensity of commerce, cultural and administrative vitality. The cities have had some of the richest economic and cultural resources that influenced its underlying urban fabric. Cities were built on a pedestrian scale and provided an extremely dense townscape, showing a high degree of complexity. The urban structure was intertwined with many ancient bazaars, commercial series and religious establishments.

It is most vital to make careful analysis of all existing and old fragments of the city and carefully integrate them into a coherent overall structure. This effort should attend to a variety of existing developments, as well as, historic references on the site, to produce an urban core with strong identity. The new development should integrate the old centers, in order to rejuvenate and restore the status and prestige of the old districts [4].

The city center and its historic character in many respects represent the symbolic heart of the city and should be reanimated to facilitate an ideal, centralized geographic position. The core of the city should be supported by an effective infrastructure emphasizing public transit and pedestrianization. This infrastructure should be expressed in community greenways and the clustering of activities which will increase pedestrian enjoyment and accessibility [5]. The center should exhibit the main focus of city activities and the main public transportation destination that will provide quick access to facilities and interchange between destinations. It will also be the hub of the pedestrian activities, since the higher density housing will be concentrated in the center. In the structure of the urban fabric, priority should be given to the clear definition of well-marked territories and spaces for various private and public uses.

\subsection{Community and neighborhood: enhance a sense of community}

Effort should be made to preserve and restore the important site historical and cultural characteristics and qualities throughout the neighborhood. A cohesive urban village quality with strong neighborhood identity is critical to a healthy, safe and sustainable community. It has been observed, that the underlying forces and internal structural process that shaped the Afghan pattern of community and city, are deeply rooted living traditions, together with religious and social philosophies, that constitute the real agents of physical developments. Therefore it is necessary for planning and design team to make a thorough analysis of these cultural sensitivities and introduce design strategies that conform to these implicit qualities [6].

The new pattern of development should emphasize a pedestrian quality environment, and the residents of the community should have convenient pedestrian accessibility to neighborhood schools, shopping, daycare and mosques, which are the activity centers of the neighborhood. The central location of neighborhood schools is critical to a walking environment. Similarly, provide physical solutions for social, recreational and religious centers, and integrate them within unified neighborhood concept.

These important neighborhood nodal activities in the area, should be connected to major pathways/ greenways, and should interweave with wetlands, 
wildlife habitat, parks, views and etc. to reprise a conscious ecological, as well as, a rich cultural experiences for the community.

Between residential developments and neighborhood amenities and services, the bike and walkways are critical to enhancing a more personal/pedestrian sense of community. These walkways should connect to convenient transit stops and should have continuous pavement patterns across driveways and streets. Provide ample bike parking on the site. Reduce auto services to a minimum 6-8 meters wide residential roadways.

Design for effective land use and density. Increased land use efficiency reduces infrastructure costs. Provide densities of at least 50 to 80 dwelling units per hectare and encourage pedestrian focus and safety.

\subsection{Cluster/subdivision development}

Preserving the integrity and identity of residential fabric are the most sensitive component of the neighborhood design and therefore, should be treated and designed compatible with the Afghan lifestyles and cultural traditions, which is strengthened through family privacy and sense of community. Cluster housing, with families of similar cultural character and life styles, shared social amenities and open spaces, can form an identifiable residential unit. Several housing prototypes (25-35 units), including row houses, low-rise apartments and in particular courtyard houses that are a traditional prototype and familiar housing form, can be grouped around defined clusters of semi-private spaces that provide a meaningful communal shared areas for the families. This model can be successful in this culture because it clearly recognizes traditional values associated with family privacy, and offer the necessary security (Figs 1 and 2) The cluster arrangement can enhance communication between the members of the community, especially the need for private areas for the neighboring female population to meet and communicate which otherwise, could not occur in the public spaces. Define for user control and responsibility, at least $60-70 \%$ of the property in the cluster and contain the territorial character of the cluster by the peripheral housing masses. This allows users to personalize residential areas and provide valuable contact between the families. Each specific realm should retain its spatial character, while interacting with neighboring units through distinct architectural features, such as intermediate gateways, and privacy buffers. The maintenance and cleaning responsibility of these areas would become the responsibility of the families in the cluster, in order to reduce cost. The families are entitled to the legal ownership of this space, provided that it is maintained as a shared domain and could not physically be encroached upon by the owners. In the neighborhoods where car ownership is prevalent, care should be given to minimize the impact of parking in the residential development. When feasible, distribute parking behind housing or in small, landscaped lots (8-12 cars), and provide parking for compact cars $(3 \times 5 \mathrm{~m})$. Shade parking spaces with canopies of trees or trellises. For rental units, lease parking spaces so households with one or no cars do not subsidize the parking for others. 


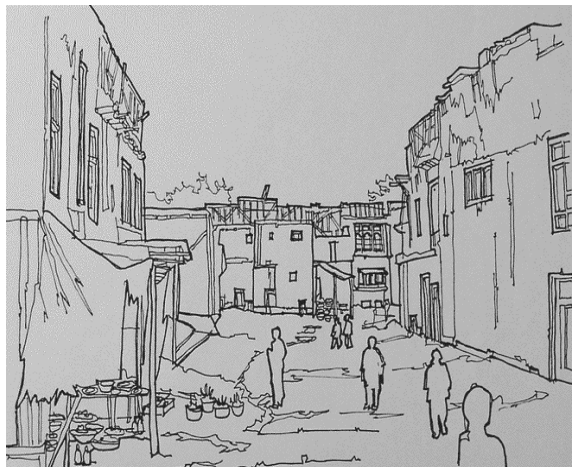

Figure 1: A residential square, Old Figure 2: City, Kabul.

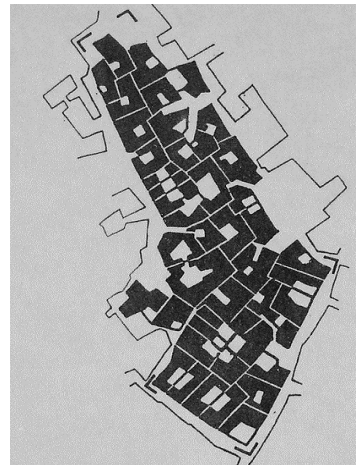

A residential segment, of courtyards, Old city, Kabul.

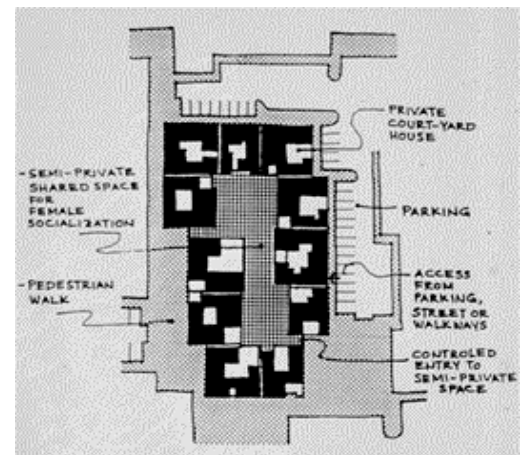

Figure 3: A proposed cluster of residential courtyards with shared semi-private space for contemporary application (Samizay and Kazimee [6]).

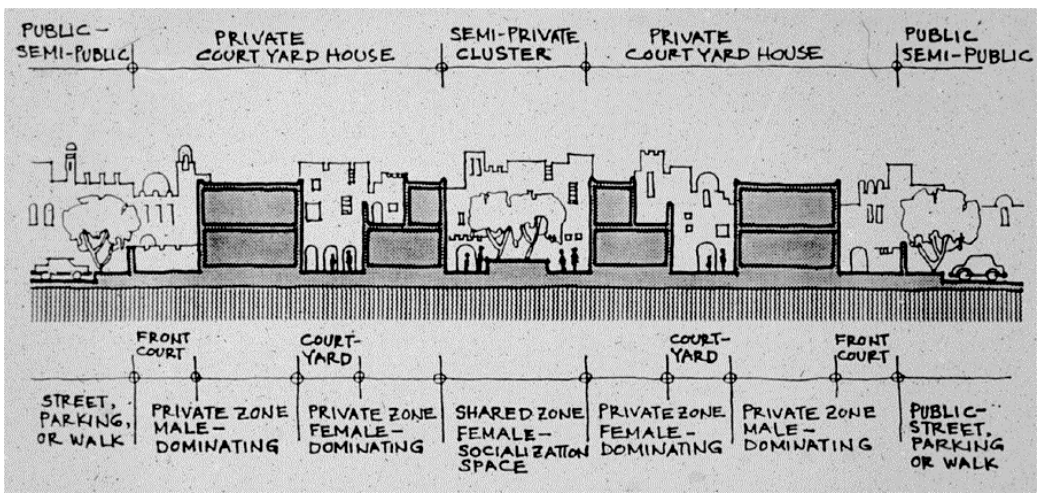

Figure 4: A cross section of a proposed residential model for contemporary application (Samizay and Kazimee [6]). 


\subsection{Dwelling unit}

Traditional Afghan architecture conceived the building as a living architectural entity in its own right, shaped according to the distinct needs of social and cultural requirements. The housing prototype that perfectly matches these cultural requirements is the introverted courtyard house. With many variations the courtyard houses are instrumental in producing the required density and an interwoven urban fabric which is typical of Afghan traditional cities (Figs 3 and 4). Each individual courtyard incorporates the necessary open space and the required access system within its respective boundaries (Fig. 5). Therefore it constituted an integral and autonomous entity with its own source of air, light, and open space, independent of the street. The introverted order of this integrated architecture container creates a sense of place that celebrates the center and provides security, peace and delight [7].

The new building practices should take into consideration the use of local technologies and local materials. The local materials are less costly and easily available, compared to imported industrial products. They are readily accessible to most of the population who are capable to build their houses through self-help (Fig. 6). Size is generally proportional to costs. Small, Efficient homes are far more affordable (both initial and long-term operating costs). Courtyards and row houses are an excellent housing prototype for effective quality living. The common wall construction can conserve up to $50 \%$ of energy and maintenance costs of a single, detached house.

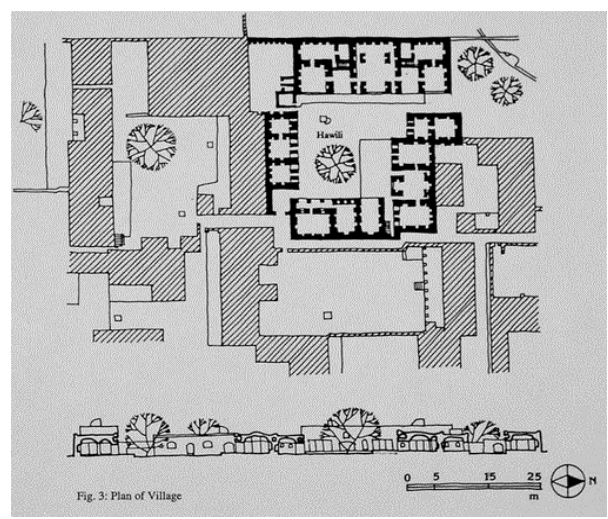

Figure 5: Traditional courtyard houses are adoptive to the cultural and environmental conditions of Afghan cities (Kazimee [8]).

\subsection{Housing availability and affordability}

The reality of assuring that every one is provided with adequate housing is most challenging task for any developing society. There is no evidence that in the cities of developing economy, the need for shelter, will fade away altogether. Squatter and slum settlements will continue to present the reality of shelter for 
the majority of people in the cities. This is so, because squatters use the traditional and vernacular ways to built their shelters. They take advantage of self-help process and participatory mechanisms that is most economical and within their means of affordability. Building with local materials and doing so incrementally to improve their houses and accommodate their growing families [8].

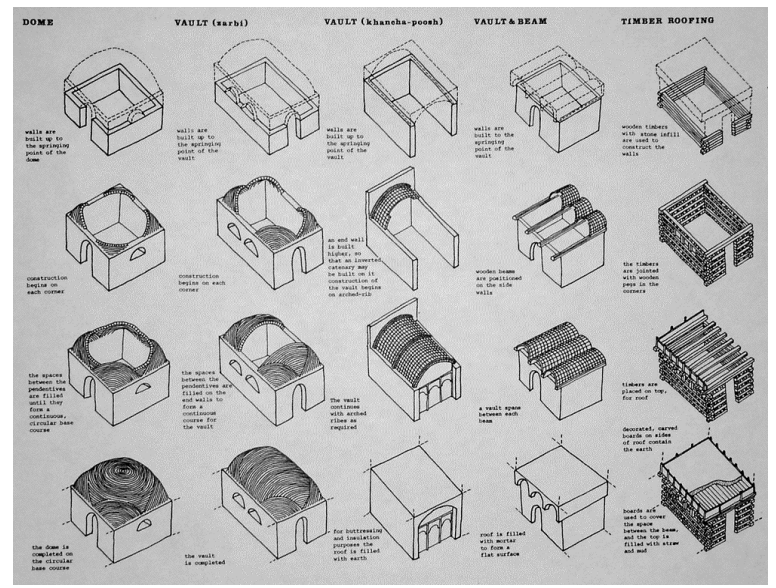

Figure 6: Traditional methods of construction and use of local materials are effective and affordable housing solutions (Kazimee [8]).

It is clear that governments must recognize the inevitable results of slum housing and mass migration to cities and take appropriate steps, such as those suggested below:

- Land ownership. Make land available with low rent for the migrants with possibility of purchase to those who are employed in a given area. Award ownership and legalize land titles to squatters who are already settled and using the site.

- Infrastructure and services. Provide an infrastructure of services (sewers, water supply, electricity and schools) before or while the settlements are being developed. This also requires an incremental process of development of these facilities in stages as funds and resources become available in time.

- Affordable financing. Assist in small financing schemes over long period of time to squatters, secured by the dwelling and land values itself. Housing cooperatives and lending organizations that are secured by the government guarantees, can be more effective in providing financial help for small self help projects, and lending to individuals to improve their dwellings rather than constructing large public housing projects.

- Participatory methods. The tradition of user participation in the planning and building process is just beginning to be appreciated and used in many societies. Offer encouragement to the self-help labor force and recognize the energies and resource that already exist in the skill and determination of people. 
Set up a self-help building advisory service to encourage higher standards of construction.

- Site and service projects. Make provisions and allocate appropriate sites for low income migrants in the city. Provide these sites with minimum infrastructure of roads, water, sewer and necessary services that can be improved and expanded progressively.

- Starter shell. Provide if possible a small room or shell with minimum space and facility on a small lot for the immediate needs of a migrant family in order to secure the first settlement process, with the goals that the room can be expanded and improved in future.

\section{Energy use and conservation}

The new building activities should recognize the natural energy systems that are at play in the built environment and aspire a symbiotic relationship with it. Learning and improving on the vernacular building principles that provided sustainable solutions to their energy needs for many generations can be a good starting point. In the hot-arid region of south and west Afghanistan, courtyard houses proved to be excellent examples of employing passive cooling strategies. Courtyards played a conscious role in the moderation of the climate in hot summer seasons and provided comfortable living conditions for the families. The central courtyard acts as a light well, as well as, an air shaft, bringing both daylight and air circulation into the rooms around it. Taking advantage of the diurnal range of temperature during the summer, at night the cool air descends into the courtyard and fills the surrounding rooms and spaces with cool air, which stays cool and comfortable throughout the day [9]. The use of wind catchers; badgir, maximize additional air circulation into the interior rooms and provide natural cross ventilation. These unique wind towers; badgers, are elaborately designed to accentuate the architectural character of the city and provide rich visual and aesthetic urban quality (Fig. 7). In the cold and mountainous climate of the north and east regions, houses are provided with elaborate under the floor heating system; tawakhana. The heat source is exhausted from a clay oven; tandur, located in the kitchen. While cooking, the auxiliary heat is circulated through continuous heating tunnels constructed under the room floors. When the worm air reaches the end of the circulation tunnels, it escapes through an outlet located on the opposite wall (Fig. 8).

The potential of vernacular solutions that are simple principles in themselves, can be a recipe for complex set of design requirements in new construction practices, to make the sustainable building energy conscious.

Conservation should be a strategy in all new building activities. Quality construction, good southern/solar exposure and efficient lighting equipment and appliances are important facts for conserving energy. Significant savings can be achieved by careful design of the dwellings. Take full advantage of passive solar strategies by providing increased windows, sun space/greenhouses and gardens on the south side of dwellings. Shade them to increase summer comfort by overhangs, trellises and or deciduous plants. 


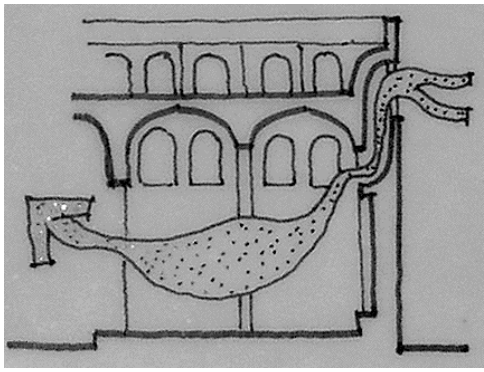

Figure 7: Badgir; traditional way of facilitating cross ventilation.

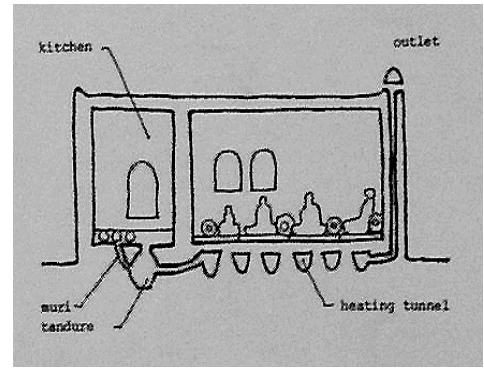

Figure 8: Tawakhana; an under the floor heating system.

Consider passive cooling methods such as clerestory (stacked) or attic ventilation, traditional wind-catcher; badgir, drawing replacement air from the cooler north side. Advancements in active systems are being made at exponential rates. The sustainable energy budget should emphasize the use of regional hydro electric power, solar and photovoltaics and wind farms in the greenbelt and rural hinterland.

\section{Land and resource conservation: critical resources for a sustainable future}

- Practice the 3 R's-Reduce, Reuse and Recycle. Provide incentives and facilities to conserve material and monetary resources. In the core of each neighborhood, provide for a recycling center and convenient recycling and composting bins in the residential cluster. Recycling is an important strategy for reducing our consumption. Encourage only the purchase of products with recycled or recyclable content by individual, corporate or community preference or policy [10].

- Design with permaculture for landscaping various open spaces and community areas. Permaculture is landscaping which is edible and perennial (fruit trees, grapevines, berry bushes, etc.). Permaculture provided beauty, low maintenance, shade and food, which can be harvested by families or community groups and sold locally for various site improvements or projects. Use Xeriscape, with indigenous landscape which requires little, additional water. Xeriscape requires less maintenance and resources [11].

\section{Water conservation: a fundamental need for human health}

Develop water impoundment areas and enhance wetlands throughout the site. Retain all water on the site as long as possible. This allows water to percolate into the ground, water landscaping, reduce downstream flooding, and increase water quality and bio-diversity. This can enhance the unique qualities of each site and provide for recreation and education opportunities. 
Use water conservation appliances. Water conservation fixtures and appliances in the home can save up to $30-70 \%$ of water use (low flush toilets, low flow faucets, water and energy efficient appliances, etc.) [12].

Harvest the rain and gray water from the house and other structures. Develop gray water storage cistern for use in landscaping and toilet flushing.

Develop artificial wetland on the site. Wetlands are economical for brown/black water treatment. This strategy applies to large and small-scale developments and is far more economical than traditional engineered water treatment facilities.

Use traditional water conservation methods where possible. The traditional method of underground cover canal: kariz, and cover cistern; hauze, proved to be effective methods of conserving and storing water for the use in dry seasons. The use of underground canals as a source for irrigation reduces the factor of evaporation in hot sunny environment.

\section{Conclusion}

The sustainable design guidelines for Afghan cities can be effective tool for demonstrating the theory, quality and application of sustainable design to urban or rural communities. These integrated design strategies permeate various defining levels of communities, integrating its natural amenities with its neighborhood context, residential, cluster and dwelling units.

The strategies are inherently a powerful research, educational and marketing tool for sustainable community planning and development. They can be used as a guide for developing a comprehensive sustainable urban program. Specific policies and strategies will vary with local conditions, but the methods for demonstrating human- environmental interchanges and benefits are universally applicable to any environment.

Adopting these recommendations in a systematic manner will provide significant long term resource and monetary savings for the communities. These savings can be retained in the communities instead of exporting to pay for imported resources and energy. This way of planning and building fosters a sustainable economy. The implementation of sustainable program will require collaboration with government, civic organizations and private individuals. All decisions should be brought into a democratic discussion with community leaders and negotiated politically with the users. Clear definitions and realistic measures by the governments and policymakers can determine the effectiveness of these programs. The process should be enhanced by grass root effort, demonstration projects and presenting and lobbying of governmental and community leaders.

\section{References}

[1] Bartuska, T.; Kazimee, B. and Owen, M. 1995. "Envisioning a Sustainable Community," Universe, Washington State University, WA.1995. 
[2] Szabo, A \& Barfield, T. "Afghanistan: An Atlas of Indigenous Domestic Architecture"," University of Texas Press, Austin TX. 1991.

[3] Bartuska, T.; Kazimee, B. and Owen, M. 1995. "Envisioning a Sustainable Community," Universe, Washington State University, WA. 1995.

[4] Bianca, Stefano. "Urban Form in the Arab World," Thames \& Hudson, UK, 2000.

[5] Bartuska, T.; Kazimee, B. and Owen, M. 1995. "Envisioning a Sustainable Community," Universe, Washington State University, WA. 1995.

[6] Samizay, R. \& Kazimee, B. "Life In Between the Residential Walls in Islamic Cities," Housing Design, Research, Education, pp. 221-238, Bulos, M. and Teymur, N. Avebury Ashgate Publishing Limited, UK, 1993.

[7] Bianca, Stefano. "Urban Form in the Arab World," Thames \& Hudson, UK, 2000.

[8] Kazimee, B. "Quest for Shelter: Squatters and Urbanization Throughout the World," in The Built Environment, Bartuska, T. and Young, G. coeditors, Crisp Publication, Inc., Menlo Park, California 1993.

[9] Talib, K. "Shelter in Saudi Arabia," Academy Edition, St Martin's Press, UK, 1984.

[10] Bartuska, T.; Kazimee, B. and Owen, M. 1995. "Envisioning a Sustainable Community," Universe, Washington State University, WA. 1995.

[11] Vieria, 1993. "A Checklist for Sustainable Developments," Building Connections: Livable, Sustainable Communities, American Institute of Architects, Washington, D.C.

[12] Mollison, B., 1990. Permaculture: A Practical Guide for a Sustainable Future, Washington, D.C. 